\title{
Polyurethanes based on thermoreversible networks designed by Diels-Alder reaction
}

\author{
O. Ursache, C. Gaina*, V. Gaina \\ ‘Petru Poni’ Institute of Macromolecular Chemistry, RO-700487 Iasi, Romania
}

Received 18 November 2016; accepted in revised form 19 January 2017

\begin{abstract}
Urethane bismaleimides (BMIs) were used in order to obtain crosslinked structures by their reaction with an aromatic trifuran compound. The Diels-Alder (DA) reaction between the maleimide and furan moieties was investigated using proton nuclear magnetic resonance $\left({ }^{1} \mathrm{H}-\mathrm{NMR}\right)$ spectroscopy for a model compound (CTF), due to the fact that the networks are insoluble in usual NMR solvents. The structure of the networks was confirmed by infrared spectroscopy. Thermal properties were investigated (by means of differential scanning calorimetry (DSC) and thermogravimetrical analyses (TGA)) and compared with the ones of similar compounds, previously obtained from the same BMIs and a different trifuran compound (which contains tertiary nitrogen in its structure). Mechanical and rheological properties were also investigated. The influence of the nature of the polyol from the BMIs structure and/or the influence of using a trifurylic compound with or without tertiary nitrogen on the properties of the crosslinked networks were also discussed.
\end{abstract}

Keywords: thermal properties, Diels-Alder reaction, polyurethanes, network, thermoreversibility

\section{Introduction}

Polyurethanes appeared as a Bayer's response to the successful development of high molecular weight polyamides by E.I. Dupont, given the competition between the two companies. The need for PUs steadily increased ever since then, because of its high abrasion, chemical resistance, flexibility, and good mechanical property [1]. Nowadays they are considered one of the most versatile polymeric materials class since they can be used in many forms and in a large number of applications including elastomers [2-5], flexible and rigid foams [6-8], biomedical applications [9-11], adhesives and coatings [12-14], polymers for electronics [15], etc. The reaction between diisocyanates or multiisocyanates and di- or polyols generates polyurethanes with different molecular structures varying from linear to crosslinked ones depending on the structure, functionality and stoichiometry of the reactants. These thermosetting polymers cannot be reprocessed or reused if, according to the desired applications, chemical crosslinkers are used [16]. For de-crosslinking of polyurethane networks, dynamic covalent chemistry is used, especially by means of the DA and retro-DA (rDA) reactions [17]. Due to its reversibility the DA reaction also represents a choice to create self-healing properties for polymer networks [18].

Concerning polyurethane, the DA reaction was employed in thermally remendable linear polymers [1922] and thermally reversible networks [23-27]. The latter were designed in three different ways: i) by polymerization reaction of monomers containing maleimide-furan cycloadduct [26, 28], ii) by crosslinking of linear polyurethane containing furan or maleimide pendant groups $[27,29,30]$ and iii) by cycloaddition DA reaction between polyurethane containing furan end groups and multimaleimide monomers $[19,23-25,31-33]$.

$\overline{{ }^{*} \text { Corresponding author, e-mail: gcost@icmpp.ro }}$

(C) BME-PT 
In a previous work we synthesised polyurethane networks (NPU) from a trifurylic compound containing a tertiary nitrogen and urethanic bismaleimide and studied their thermal properties [34]. Taking into account the fact that the DA reaction could be affected by the presence of the tertiary nitrogen which can activate the maleimide double bond (leading to the homopolymerization of bismaleimides) [35], in this work we prepared analogues networks from the same BMI and a different trifurylic compound (without tertiary nitrogen) in order to see how this influences their properties. Additionally to the thermal properties, the mechanical and rheological ones were studied and also the crosslinking densities were evaluated.

\section{Experimental part}

\subsection{Measurements}

The Fourier transform infrared (FTIR) spectra were recorded on a Bruker Vertex 70 Instruments (Austria) equipped with a Golden Gate single reflection ATR accessory, spectrum range $600-4000 \mathrm{~cm}^{-1}$.

The proton nuclear magnetic resonance $\left({ }^{1} \mathrm{H}-\mathrm{NMR}\right)$ spectra were recorded on a Bruker NMR spectrometer, Avance DRX $400 \mathrm{MHz}$ (Rheinstteten, Germany), using $\mathrm{CDCl}_{3}$ and DMSO- $d_{6}$ as solvent and tetramethylsilane as an internal standard.

DSC measurements were conducted on a DSC 200 F3 Maia (Netzsch, Germany). A mass of $10 \mathrm{mg}$ of each sample was heated in pressed and pierced aluminium crucibles at a heating rate of $10^{\circ} \mathrm{C} / \mathrm{min}$. Nitrogen was used as inert atmosphere at a flow rate of $50 \mathrm{~mL} / \mathrm{min}$. The heat flow versus temperature was recorded. The baseline was obtained by scanning the temperature domain of the experiments with an empty pan. The enthalpy was calibrated with indium according to standard procedure.

The rheological measurements were performed using a controlled stress Bohlin CVO Rheometer (Malvern Instruments UK) with parallel plate geometry $(60 \mathrm{~mm}$ diameter and $500 \mu \mathrm{m}$ gap) and thermal control by Peltier effect. The experiments were carried out within the linear viscoelastic regime under the dynamic oscillation mode using a $1 \mathrm{rad} / \mathrm{s}$ frequency. Experiments were run from 70 to $140{ }^{\circ} \mathrm{C}$ at a $1{ }^{\circ} \mathrm{C} / \mathrm{min}$ heating rate constant.

TGA experiments were conducted on a STA 449 F1 Jupiter apparatus (Netzsch, Germany). 10 mg of sample was heated in an open alumina crucible in nitrogen atmosphere with a flow rate of $50 \mathrm{~mL} / \mathrm{min}$. A heating rate of $10^{\circ} \mathrm{C} / \mathrm{min}$ was applied.
Stress-strain measurements were performed on a test apparatus, Shimadzu AGS-J, cell load 1kN (Japan). Measurements were run at an extension rate of $10 \mathrm{~mm} / \mathrm{min}$, at room temperature $23^{\circ} \mathrm{C}$. All samples were measured three times and the averages were obtained. The samples were $3 \mathrm{~mm}$ width, and $0.05-$ $0.15 \mathrm{~mm}$ thickness; the gauge length was $20 \mathrm{~mm}$. The swelling degree $\left(D_{\mathrm{s}}\right)$ was measured by soaking a film (width $5 \mathrm{~mm}$, length $5 \mathrm{~mm}$, thickness $0.1-$ $0.15 \mathrm{~mm}$ ) in water, NMP/water (vol./vol. 1/1), Dioxane/water (vol./vol. 1/1), NMP, or Dioxane at room temperature for $70 \mathrm{~h}$ using the following equation: $D_{\mathrm{s}}[\mathrm{wt} \%]=100\left(w_{1}-w_{0}\right) / w_{0}$, where $w_{0}$ is the initial weight of the film and $w_{1}$ is the weight of the swollen film after soaking.

\subsection{Reagents and materials}

2-Furfurylamine, 2-furfurylalcohol, 2-furfuryl glycidyl ether, bis(2 -aminopropyl)polypropylene glycol-block-polyethylene glycol-block-propylene glycol, $M_{\mathrm{n}}=1900$ (Jeffamine ED-2003) (Aldrich), polyethylene glycol 2000 (PEG-2000), 20\% solution of triphenylmethane triisocyanate in methylene chloride, triethylamine purchased from Aldrich Company and used as received. Dimethylformamide (DMF), chloroform, dichloromethane were distilled before uses.

\section{Synthesis of bismaleimide containing urethane moieties BMI-(a-e)}

The bismaleimide BMI-(a-e) were prepared from polyester glycols (poly(ethylene adipate) PEA-2000, poly(buthylene adipate) PBA-2000, , polycaprolactone diol PCD-2000), poly(tetramethylene ether) glycols (PTHF-2000) or Jeffamine ED-2003 with 4maleimidophenyl isocyanate according to a method described elsewhere [34, 36]. The structures of BMI(a-e) are presented in Table 1.

\section{Preparation of trifuran compounds TF-(1,2)}

Synthesis of TF-1 was described in our previous article [34]

Tris(2-furylmethyl)[methanetoiyltris(4,1-phenylene)] triscarbamate, TF-2 was prepared by the addition reaction of triphenylmethane triisocyanate to 2-furfurylalcohol in molar ratio of 1:3. A typical procedure is presented below. To a solution of $20 \%$ triphenylmethane triisocyanate $(0.0272 \mathrm{~mol}, 50 \mathrm{~mL})$ in methylene chloride and DMF (50 mL), 2-furfurylalcohol $(0.0818 \mathrm{~mol}, 7.15 \mathrm{~mL})$ and four drops of triethylamine as catalyst were added and the solution was 
Table 1. Structures of BMI-(a-e)

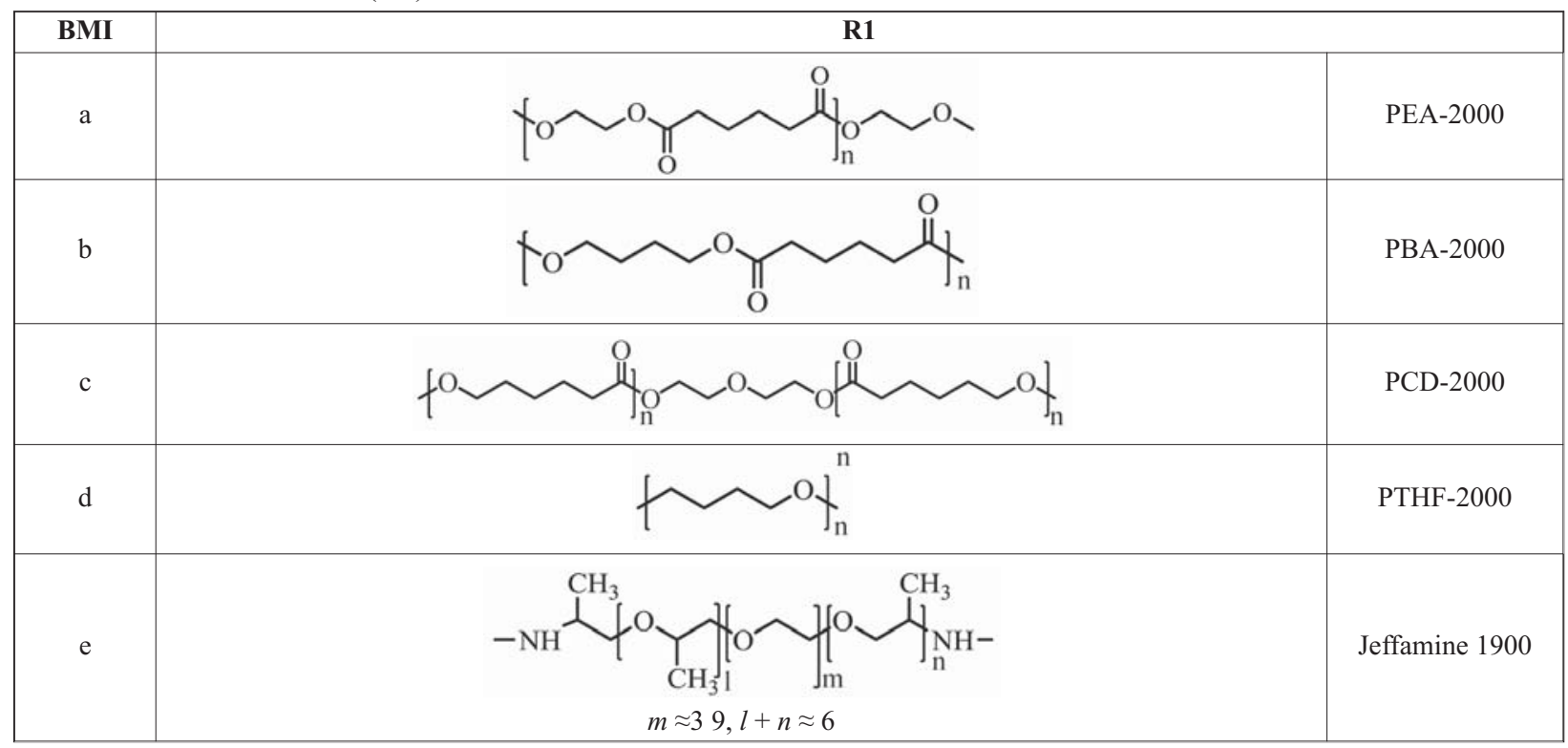

Table 2. Composition of polyurethane networks

\begin{tabular}{|c|c|c|c|}
\hline TF & R2 & BMI & NPU \\
\hline \multirow{5}{*}{1} & \multirow{5}{*}{ 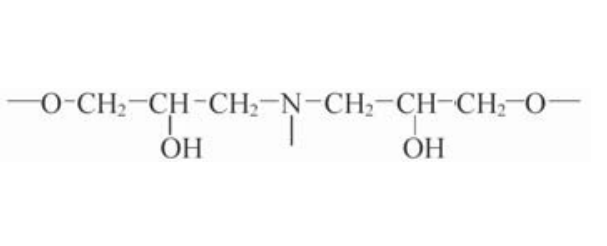 } & a & $1 \mathrm{a}$ \\
\hline & & $\mathrm{b}$ & $1 \mathrm{~b}$ \\
\hline & & $\mathrm{c}$ & $1 \mathrm{c}$ \\
\hline & & $\mathrm{d}$ & $1 \mathrm{~d}$ \\
\hline & & $\mathrm{e}$ & $1 \mathrm{e}$ \\
\hline \multirow{5}{*}{2} & \multirow{5}{*}{$-\mathrm{OOCHN}$} & $\mathrm{a}$ & $2 \mathrm{a}$ \\
\hline & & $\mathrm{b}$ & $2 \mathrm{~b}$ \\
\hline & & $\mathrm{c}$ & $2 \mathrm{c}$ \\
\hline & & $\mathrm{d}$ & $2 \mathrm{~d}$ \\
\hline & & $\mathrm{e}$ & $2 \mathrm{e}$ \\
\hline
\end{tabular}

stirred at $60^{\circ} \mathrm{C}$ for 4 hours. The methylene chloride was evaporated out with a rotary evaporator and the solution in DMF was precipitated in methanol, washed with methanol and dried at $60^{\circ} \mathrm{C}$ for 12 hours in a vacuum oven.

TF-2 gives a brown solid, 95\% yield.

FTIR spectrum $\left(\mathrm{KBr}\left[\mathrm{cm}^{-1}\right)\right.$ : $3390,3313,1713$, $1595,1526,1412,1315,1220,1046,817$, and 744. ${ }^{1} \mathrm{H}-\mathrm{NMR}$ spectrum (DMSO- $\left.d_{6}, \mathrm{TMS}\right), \delta$ [ppm]: 9.73 (s, NH), $7.72\left(\mathrm{~s}, 3 \mathrm{H}, \mathrm{C}_{4}-\underline{\mathrm{H}}\right.$ furan ring), 7.38 (d, $J=$ $8.0 \mathrm{~Hz}, 6 \mathrm{H}$, aromatic protons), $7.01(\mathrm{~d}, J=8.0 \mathrm{~Hz}, 6 \mathrm{H}$, aromatic protons), $6.50-6.28(\mathrm{~d}, 6 \mathrm{H},=\mathrm{C} \underline{\mathrm{H}}-\mathrm{C} \underline{\mathrm{H}}=$ from furan ring), 5.39 (s, 1H, $\underline{\mathrm{H}}), 5.12$ (s, 6H, $\mathrm{C}_{2}$-furan).

\section{Synthesis of model compound}

The model compound (CTF) was prepared by the cycloaddition reaction of TF-2 to p-acetyl phenylmaleimide in molar ratio of 1:3, in THF at reflux for 20 hours.

\section{CTF}

${ }^{1} \mathrm{H}-\mathrm{NMR}$ spectrum (DMSO- $d_{6}$, TMS), $\delta[\mathrm{ppm}]: 9.74$ (s, 3H, NHCOO), 8.09-8.07 (d, 6H, aromatic protons ortho $\left.-\mathrm{CO}-\mathrm{CH}_{3}\right), 7.36-7.40(\mathrm{dd}, 12 \mathrm{H}, 6 \mathrm{H}$, aromatic protons ortho imide and $6 \mathrm{H}$ aromatic protons ortho $-\mathrm{NH}), 7.01(\mathrm{~s}, 6 \mathrm{H}$, aromatic protons ortho $-\mathrm{CH}), 6.72-$ $6.62(\mathrm{dd}, 6 \mathrm{H},-\mathrm{CH}=\mathrm{CH}-$ endo + exo cycloadduct), 5.42 (s, 1H, >CH-phenyl), 5.30 (s, 3H, $-\mathrm{CH}$ cycloadduct), $4.99-4.48\left(\mathrm{~m}, 6 \mathrm{H},-\mathrm{CH}_{2}-\right.$ exo + endo cycloadduct), 3.90-3.67 (dd, $>\mathrm{CH}-\mathrm{CH}<$ endo cycloadduct), 3.24-3.22 ( $\mathrm{d},>\mathrm{CH}-\mathrm{CH}<$ exo cycloadduct), $2.62\left(\mathrm{~s}, 9 \mathrm{H},-\mathrm{CH}_{3}\right)$.

\section{Synthesis of polyurethane networks NPU-1,2(a-e)}

All adducts were synthesized from stoichiometric amount of the furan functional groups (TF-1,2) and bismaleimide BMI-(a-e). The mixture was stirred at $110^{\circ} \mathrm{C}$ for 1 hour in a necked flask in DMF under nitrogen atmosphere. Then, the temperature was 
decreased at $80^{\circ} \mathrm{C}$ and maintained for 6 hours. Finally the polymer solution was cast on glass plates at $80^{\circ} \mathrm{C}$ and maintained for 10 hours. The thickness of films was about $0.7-1.2 \mathrm{~mm}$.

\section{Results and discussion}

The DA reaction of the trifuran compounds TF-(1,2) and urethane bismaleimides BMI-(a-e), as depicted in Figure 1 and Table 1 and 2, was used in order to obtain crosslinked thermoreversible polyurethane networks NPU-1,2(a-e). Since the crosslinked networks are insoluble in NMR solvents, for facilitating the investigation by NMR spectroscopy of the DA and retro-DA reactions of trifuran compound with bismaleimide, a model compound, CTF, was synthesized (Figure 2). The spectral results confirmed the expected structure. So, in the ${ }^{1} \mathrm{H}-\mathrm{NMR}$ spectrum of compound CTF (Figure 3a) it was observed the presence of both endo and exo forms of DA adduct: the $\mathrm{H} 4$ exo protons appear at $3.22-3.24 \mathrm{ppm}$, while the endo ones are present at $3.67-3.90 \mathrm{ppm}$, the exo and endo protons from the $\mathrm{CH}_{2}$ linked to the adduct are between 4.99-4.48, the exo/endo $\mathrm{H} 3$ protons are those at 5.29 and $5.4-5.44 \mathrm{ppm}$ and $\mathrm{H} 1, \mathrm{H} 2$ endo/exo appear at $6.62-6.72 \mathrm{ppm}$. The exo form of cycloadduct is formed majority since its formation is thermodynamically favoured. When heating $\mathbf{C T F}$ at $150^{\circ} \mathrm{C}$ for 1 hour the retrodienic reaction takes place and the debonding of the cycloadduct was evidenced in the ${ }^{1} \mathrm{H}-\mathrm{NMR}$ spectrum by the disappearance of the characteristic protons' chemical shifts.

The ${ }^{13} \mathrm{C}-\mathrm{NMR}$ spectrum of compound CTF (Figure $3 \mathrm{~b}$ ) and the one of the debonded adduct (CTF heated at $150{ }^{\circ} \mathrm{C}$ ) confirm the formation of the exo/endo forms of the cycloadduct and the occurrence of the $\mathrm{rDA}$ reaction.

In order to demonstrate the occurrence of DA reaction when obtaining the crosslinked networks a $9 \cdot 10^{-3} \mathrm{~mol} / \mathrm{L}$ solution in DMSO- $d_{6}$ of BMI-d and

TF-2 was prepared and the ${ }^{1} \mathrm{H}-\mathrm{NMR}$ was recorded. Then the mixture was heated at $80^{\circ} \mathrm{C}$ for $5 \mathrm{~h}$ and the spectra were recorded after each hour of reaction. The spectra are represented in Figure 3c, and the appearance of characteristic peaks of the cycloadduct can be observed. The reaction was not completed for the NMR experiment due to the insolubility of the final product, so in the spectra from Figure $3 \mathrm{c}$ there is a mixture of initial monomers and NPU-2d.

The structure of the network films was studied with ATR-FTIR spectroscopy. In Figure 4 there are represented for exemplification the spectra of NPU-1(a-e). The formation of the cycloadduct is confirmed by the appearance of the absorption peak characteristic to
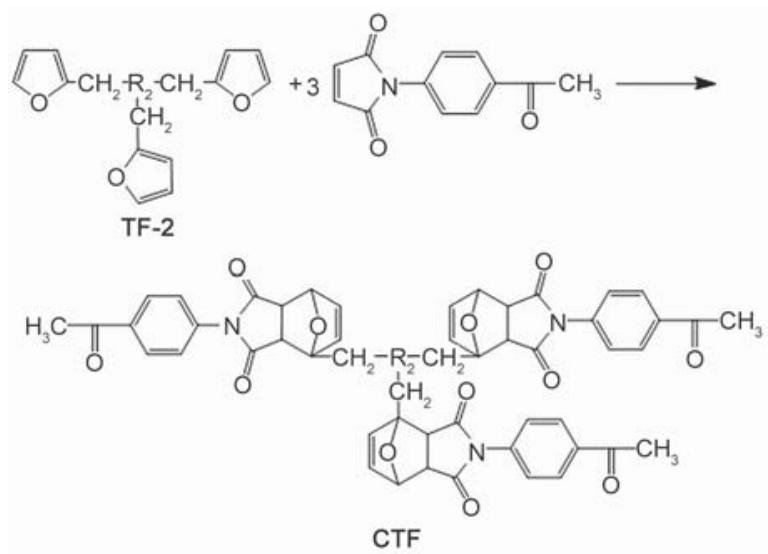

Figure 2. Synthesis of model compound CTF<smiles>CC=CC(=O)N1C(=O)C=C(C)C1=O</smiles>

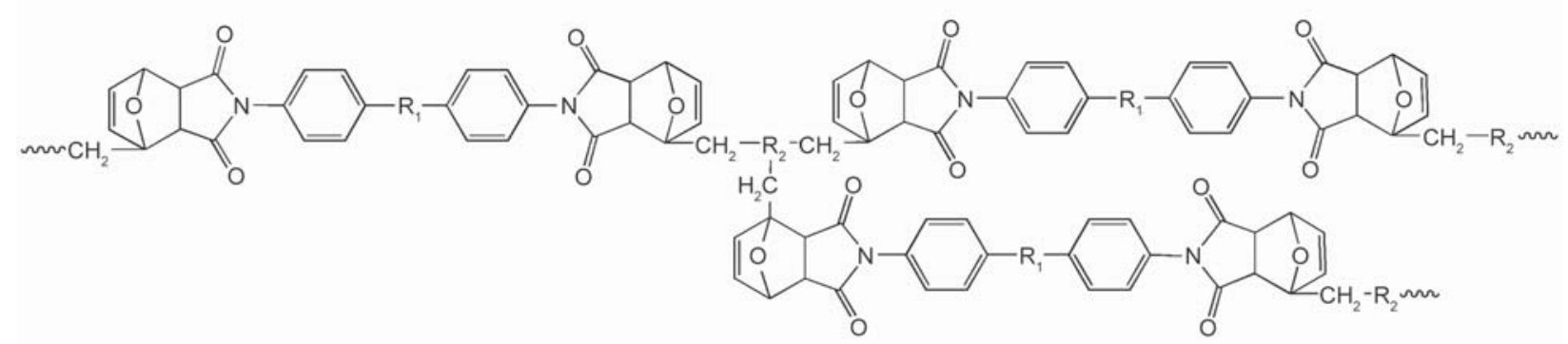

NPU-1,2(a-e)

Figure 1. Synthesis of NPU-1,2(a-e) networks 

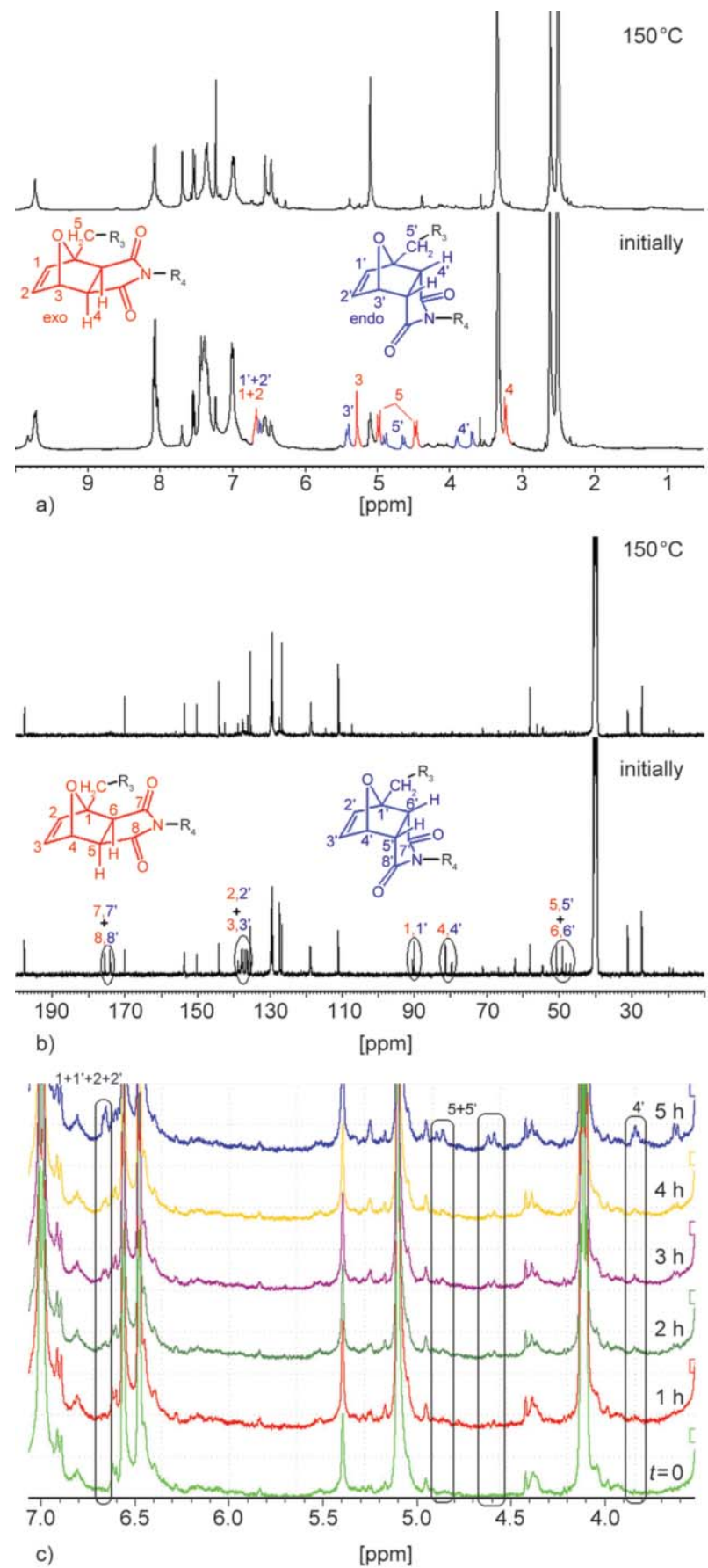

Figure 3. a) ${ }^{1} \mathrm{H}-\mathrm{NMR}$ spectra of model compound (initially and at $\left.150{ }^{\circ} \mathrm{C}\right)$, b) ${ }^{1} \mathrm{C}-\mathrm{NMR}$ spectra of model compound (initially and at $150^{\circ} \mathrm{C}$ ), c) ${ }^{1} \mathrm{H}-\mathrm{NMR}$ spectra representing the DA reaction evolution for NPU$\mathbf{2 d}$; the assignment of the cycloadduct's protons is similar as in the case of CTF (Figure 3a)

L1 it as a shoulder at $1776 \mathrm{~cm}^{-1}$. Also there can be obL2 served the disappearance of the absorption band speL3 cific to the furan ring breathing (at about $1013 \mathrm{~cm}^{-1}$ ). L4 Other peaks specific to the structures NPU-1(a-e) L5 can be also observed at $1517 \mathrm{~cm}^{-1}$ (disubstituted L6 phenyl ring), around $1100 \mathrm{~cm}^{-1}(\mathrm{C}-\mathrm{O}-\mathrm{C}$ of polyol ureL7 thane bismaleimide), 3330 and $1544 \mathrm{~cm}^{-1}$ ( $\mathrm{NH}$ of

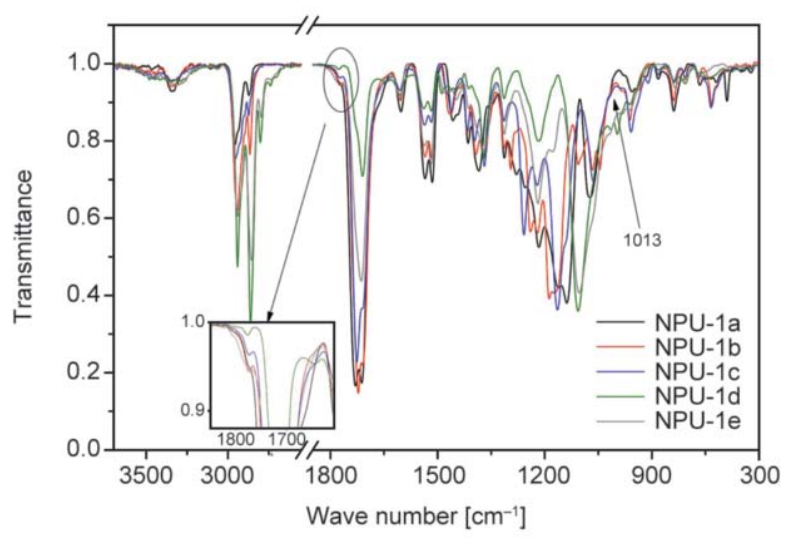

Figure 4. ATR-FTIR spectra of networks NPU-1(a-e)

urethane groups). The $\mathrm{CO}$ absorption band for networks based on polyester diols appeared shifted to $1723-1733 \mathrm{~cm}^{-1}$ in comparison with that of cycloadducts based on polyether diols which appeared around $1709-1715 \mathrm{~cm}^{-1}$.

\subsection{DSC}

DSC analysis was utilised in order to get information about the glass transitions, crystallization, melting endotherms and also the thermoreversible character of the crosslinked networks (Figure 5 and 6 ) and the obtained data for NPU-2(a-e) are listed in Table 3, NPU-1(a-e) were discussed in our previous work. The DSC scans for the compounds are represented in Figure 5. One can observe the presence of two processes during the heating of all samples: first the glass transition of the soft segments (from the polyol of urethane BMI) followed by the disconnection of the Diels-Alder cycloadduct. The glass transition temperature of the soft segment varied between -75.10 and $-15.78^{\circ} \mathrm{C}$. The PTHF based network present the lowest $T_{\mathrm{g}}$ of the soft segment due to a better microphase separation comparing with the polyesters based networks. The $T_{\mathrm{g}}$ of the soft segment increases in the order $\mathrm{PTHF}<\mathrm{PBA}<\mathrm{PCD}<\mathrm{PEA}<$ Jeffamine, the same variation in different compounds based on these polyols being previously observed [37]. NPU-2(b-d) networks based on PBA, PCD and PTHF also present an exothermic peak between -20.68 and $22.67^{\circ} \mathrm{C}$ indicating the crystallization of soft segments followed by an endotherm ranged between $12.25-44.32^{\circ} \mathrm{C}$ appeared due to the melting of crystalline domains of soft segments. The last endotherm, ranged between 138.9-141.64 ${ }^{\circ} \mathrm{C}$, appears on the DSC curves of all the samples suggesting the debonding of the DA adduct. The enthalpy of this process is about 7.8$17.87 \mathrm{~J} / \mathrm{g}$. Comparing the two series of networks, 


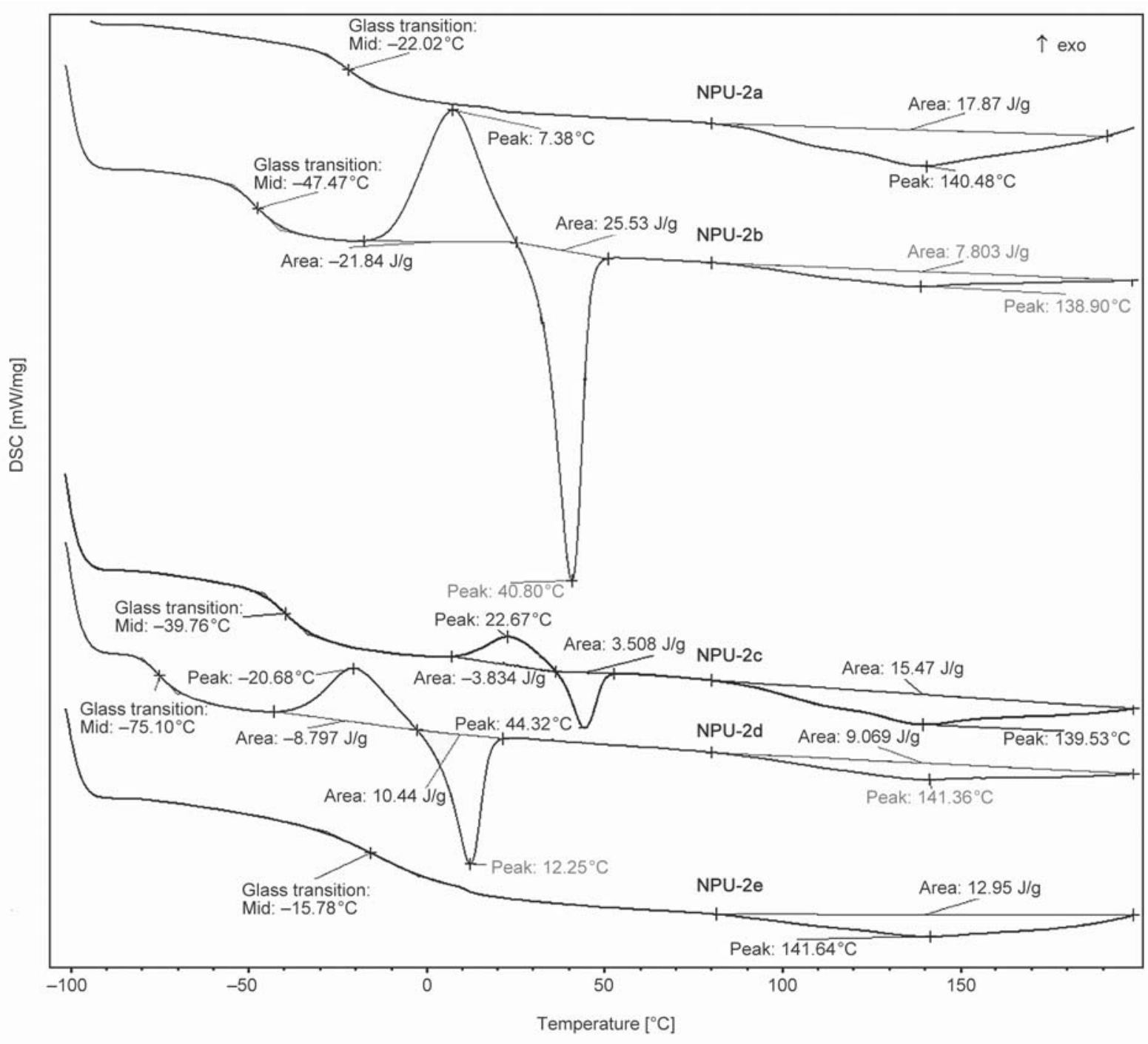

Figure 5. DSC scans for NPU-2(a-e)

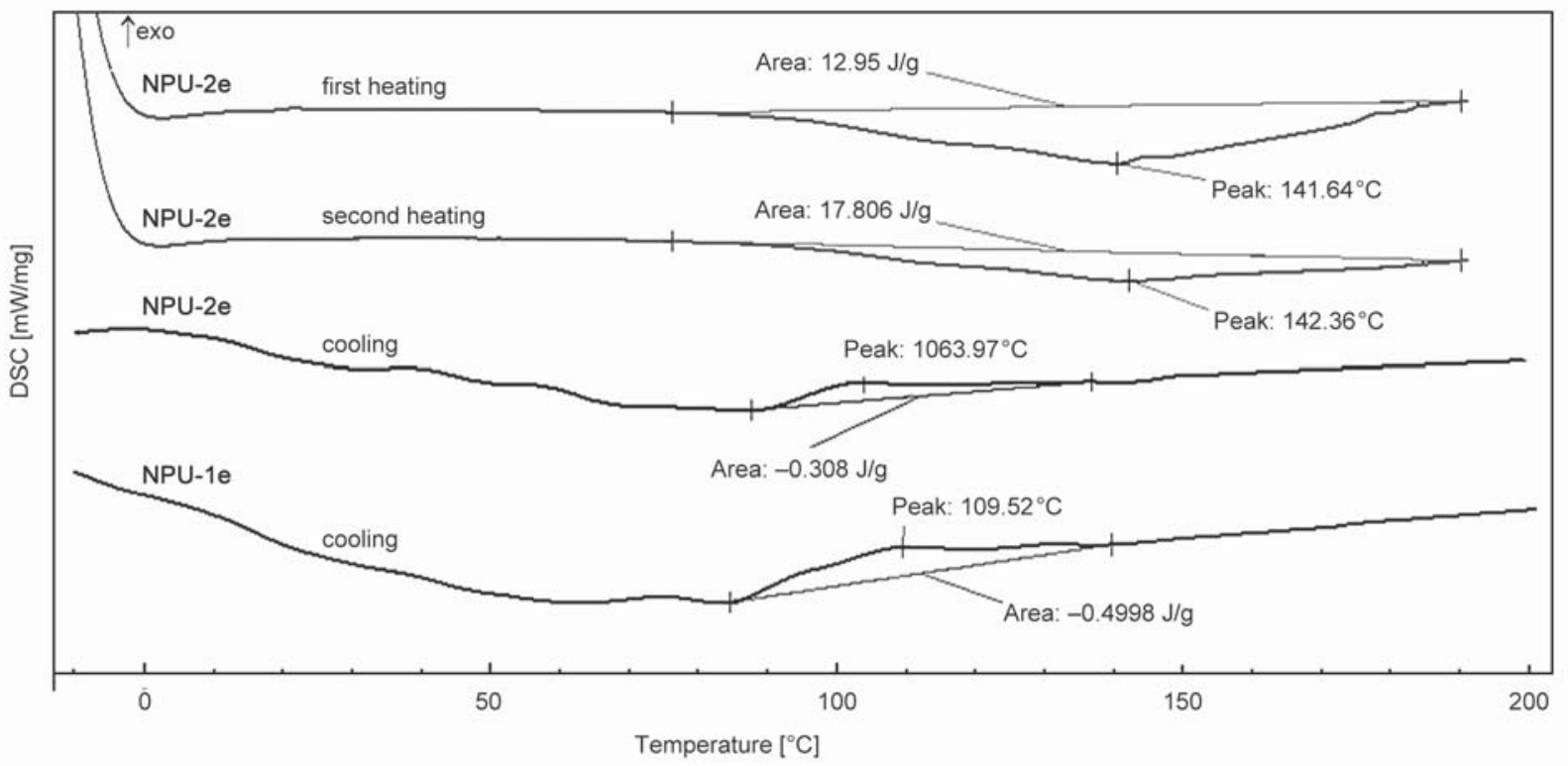

Figure 6. DSC heating-cooling-heating curves for NPU-2e and cooling curve for NPU-1e 
Table 3. Thermal behaviour of polyurethane networks

\begin{tabular}{|l|c|c|c|c|c|}
\hline Sample & $\begin{array}{c}\boldsymbol{T}_{\mathbf{g ~ s s}} \mathbf{a}^{\mathbf{a}} \\
{\left[{ }^{\circ} \mathbf{C}\right]}\end{array}$ & $\begin{array}{c}\boldsymbol{T}_{\text {cryst }}{ }^{\mathbf{b}} \\
{\left[{ }^{\circ} \mathbf{C}\right]}\end{array}$ & $\begin{array}{c}\boldsymbol{T}_{\text {endo }}{ }^{\mathbf{c}} \\
{\left[{ }^{\circ} \mathbf{C}\right]}\end{array}$ & $\begin{array}{c}\boldsymbol{T}_{\mathbf{r D A}}{ }^{{ }^{d}} \\
{\left[{ }^{\circ} \mathbf{C}\right]}\end{array}$ & $\begin{array}{c}\Delta \boldsymbol{H}_{\mathbf{r D A}}{ }^{\mathbf{e}} \\
{[\mathbf{J} / \mathbf{g}]}\end{array}$ \\
\hline NPU-1a & -25.80 & - & 36.49 & 125.27 & 58.20 \\
\hline NPU-1b & -45.98 & - & 40.20 & 123.14 & 28.49 \\
\hline NPU-1c & -34.57 & - & 52.19 & 118.88 & 45.52 \\
\hline NPU-1d & -74.49 & -33.50 & 9.68 & 130.58 & 79.76 \\
\hline NPU-1e & -40.35 & - & - & 136.52 & 19.85 \\
\hline NPU-2a & -22.02 & - & - & 140.48 & 17.87 \\
\hline NPU-2b & -47.47 & 7.38 & 40.28 & 138.90 & 7.80 \\
\hline NPU-2c & -39.76 & 22.67 & 44.32 & 139.53 & 15.47 \\
\hline NPU-2d & -75.10 & -20.68 & 12.25 & 141.36 & 9.07 \\
\hline NPU-2e & -15.78 & - & - & 141.64 & 12.95 \\
\hline
\end{tabular}

${ }^{\mathrm{a}}$ Glass transition temperature of soft segment of polyurethanes

${ }^{\mathrm{b}}$ Crystallization temperature of soft segment of polyurethanes

${ }^{\mathrm{c}}$ Endothermal peak temperature attributed to the melting of soft segment of polyurethanes

${ }^{\mathrm{d}}$ Endothermal peak temperature corresponding to rDA process ${ }^{\mathrm{e}} \mathrm{Heat}$ of rDA process

there can be noticed that the use of TF-2 instead of TF-1 in the synthesis of networks leads to a higher rDA temperature of networks which varies in the range of 138.90 and $141.64^{\circ} \mathrm{C}$. The obtained values of the $T_{\mathrm{rDA}}$ for the crosslinked networks were higher than the ones of similar networks from other studies $[38,39]$.

The thermally reversible character of the compounds can be evidenced with DSC by applying multiple heating-cooling cycles to the sample. In Figure 6 is represented a heating-cooling-heating cycle for NPU2e. The reproducibility of the endothermic peak from the heating curves demonstrates the thermoreversibility of the network. When heating the sample up to $190^{\circ} \mathrm{C}$ the disconnection of the cycloadduct takes place with the formation of maleimide and furan groups. If cooling down the sample the above mentioned groups come close together and the reconnection of adduct is possible [37, 40, 41]. This is

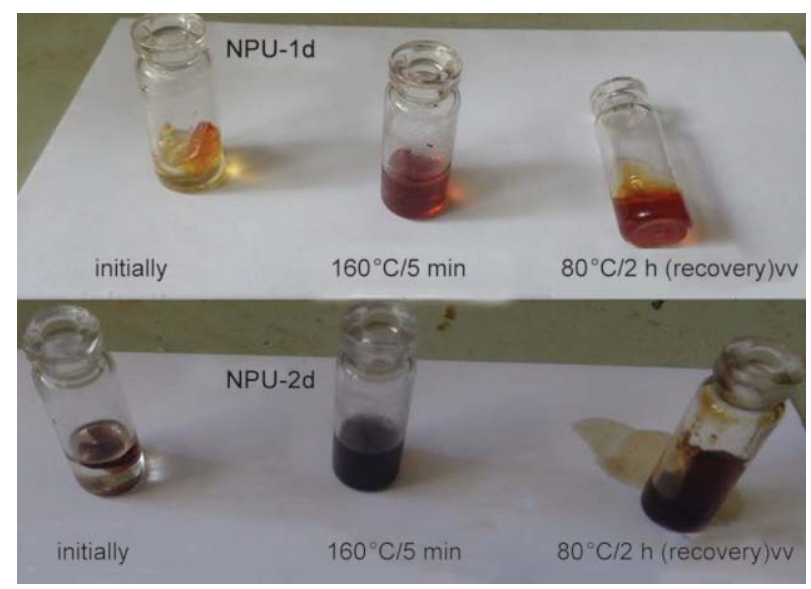

Figure 7. Picture demonstrating the thermoreversibility of samples NPU-1,2d evidenced by the exothermic peak which appears on the cooling curve. In the second heating, the breaking of the adduct takes place in the same temperature range as in the case of the first heating.

The thermoreversibility of the networks can be also observed in Figure 7 where one can see that the network film is insoluble in DMSO at room temperature, after keeping the sample for 5 minutes at $160^{\circ} \mathrm{C}$ it solubilizes (we obtain a liquid) due to the debonding of the DA adducts with the disruption of the network. Then, if keeping the solution $2 \mathrm{~h}$ at $80^{\circ} \mathrm{C}$ the reformation of the networks takes place because of the DA reaction of maleimide and furan groups, obtaining a gel.

\subsection{Rheological behaviour}

The gel point in rheological experiments is determined using various methods, according to different definitions [42, 43]: the divergence point or fixed level of the viscosity $[44,45]$, the crossover point of the dynamic storage modulus $\left(G^{\prime}\right)$ and loss modulus $\left(G^{\prime \prime}\right)$ [46], or the point at which the loss tangent becomes independent of testing frequency [47-50]. The gel point for NPU-2d, as the crossover point of $G^{\prime}$ and $G^{\prime \prime}$ appears at $116.5^{\circ} \mathrm{C}$ as can be seen in Figure 8a. Initially, $G^{\prime}$ is lower than $G^{\prime \prime}$ indicating the viscous nature of the sample; during the heating process both $G^{\prime}$ and $G^{\prime \prime}$ increased gradually. After the gel point, the storage modulus value surpasses the loss modulus ones, suggesting the switch to the dominant elastic properties of the sample. The rheological measurements were done using the starting monomers and the reaction proceeded in the instrument. So, first the DA reaction took place and the viscosity increased. Then, we suppose a competition between the DA and rDA reactions proceeded, explaining this way the increasing trend of viscosity. One can also observe in the DSC experiments that on the heating/cooling curves the values of the endothermal and exothermal domains overlap. Other rheological studies from the literature on DA networks were done by cooling the debonded crosslinked networks [51]. For comparing the two series in Figure $8 \mathrm{~b}$ the viscosity of NPU-1e and NPU-2e vs. time is represented. One can see that in the case of the network based on the trifurylic compound with tertiary nitrogen (NPU-1e) the gelation begins earlier, at a lower temperature and finishes at a higher one than in the case of NPU-2e network. So, the Diels-Alder reaction needs a longer time to proceed. This fact was also confirmed by the DSC 

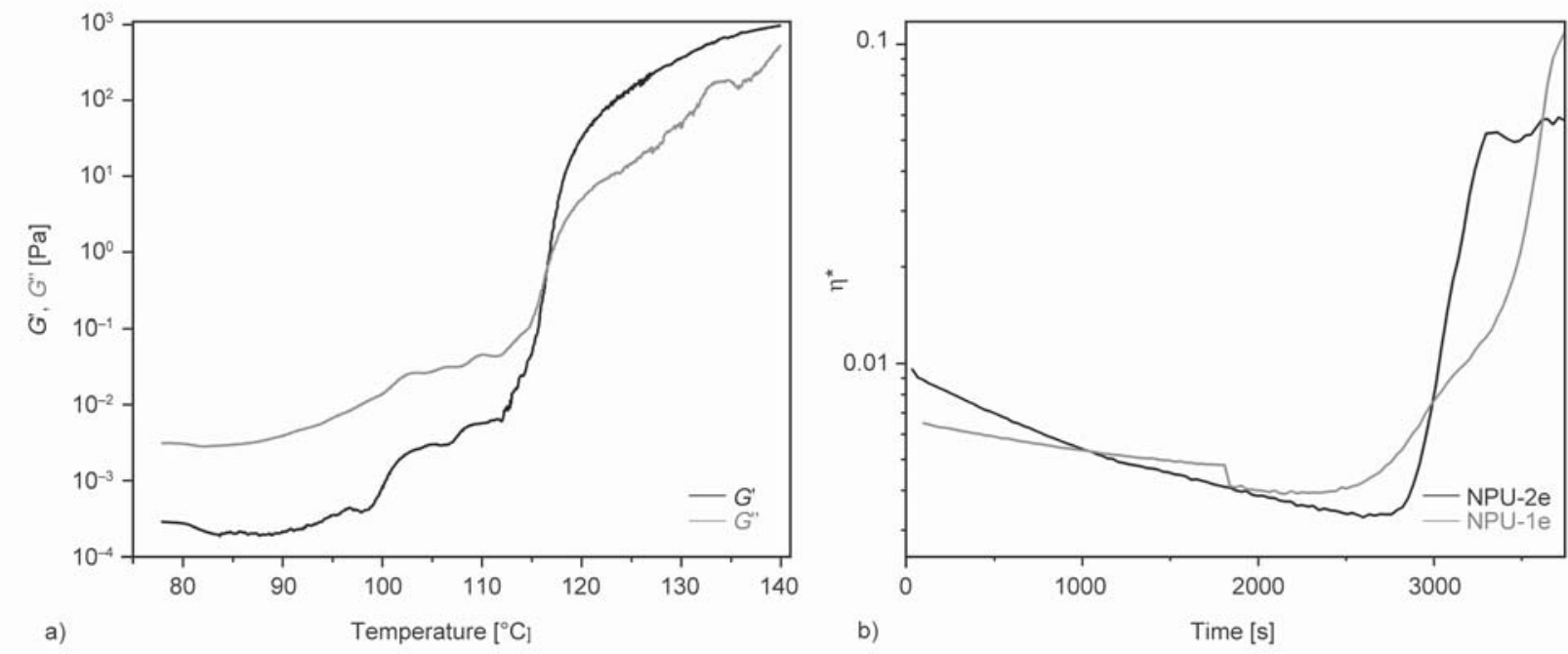

Figure 8. a) Dynamic storage modulus $\left(G^{\prime}\right)$ and loss modulus $\left(G^{\prime \prime}\right)$ evolution with increasing temperature for NPU-2e, b) Viscosity vs temperature curves for NPU-1,2e

experiment, where on the cooling curves of these samples (Figure 6) the exothermic peak corresponding to dienic reaction is larger in the case of NPU-1e.

\subsection{TGA}

Table 4 present the parameters extracted from the thermo gravimetric analyses, while the TG and DTG curves of the new networks are depicted in Figure 9. From the figure, as well from the table, the influence

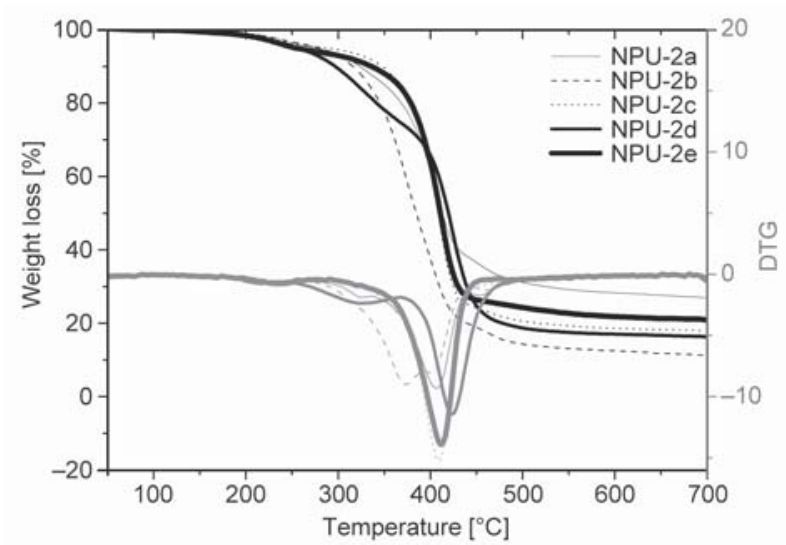

Figure 9. TG and DTG curves for NPU-2(a-e) of the structural nature of the substituents on the thermal stability may be observed. So, degradation begins faster in the case of NPU-2d based on the BMI which contains poly(tetramethylene ether) glycol, while NPU-2b (obtained from the maleimide with poly(buthylene adipate)) is stable up to $221^{\circ} \mathrm{C}$. NPU-2a has the highest char yield and NPU-2b the lowest. The thermal decomposition stages are similar to those of NPU-1(a-e) described in our previous work [34]. The IDT of the new synthesised networks compared with NPU-1(a-e) series are lower due to higher urethane group concentrations.

\subsection{Mechanical properties}

Young's modulus, maximum strength and maximum strain of all the samples are shown in Figure 10 and Table 5. When using TF-2 in the synthesis of NPU instead of TF-1 the flexibility of the molecular chains decreased due to the introduction of aromatic rings and also to the higher number of hydrogen bonds. Therefore, the Young's moduli of NPU-2(a-e) are higher than the ones of the corresponding NPU-1

Table 4. The thermogravimetric data for the polyurethane networks

\begin{tabular}{|c|c|c|c|c|c|}
\hline \multirow[t]{2}{*}{ Sample } & \multirow{2}{*}{$\begin{array}{l}\text { IDT }^{\mathbf{a}} \\
{\left[{ }^{\circ} \mathbf{C}\right]}\end{array}$} & \multicolumn{3}{|c|}{$\begin{array}{l}\text { Decomposition temperature range (weight losses) } \\
\qquad\left[{ }^{\circ} \mathrm{C}\right][\%]\end{array}$} & \multirow{2}{*}{$\begin{array}{c}Y_{\mathrm{c}}^{\mathrm{b}}\left(\mathbf{7 0 0}{ }^{\circ} \mathrm{C}\right) \\
{[\%]}\end{array}$} \\
\hline & & stage I & stage II & stage III & \\
\hline NPU-2a & 204.46 & $228.69(6.15)$ & $325.12 \quad(9.01)$ & $\begin{array}{l}406.52(45.89) \\
452.56(13.25)\end{array}$ & 26.66 \\
\hline NPU-2b & 221.11 & $232.84(4.40)$ & $374.25(64.50)$ & $463.97(11.39)$ & 10.92 \\
\hline NPU-2c & 215.67 & $233.04(4.44)$ & $409.03(54.07)$ & $469.98 \quad(9.71)$ & 17.71 \\
\hline NPU-2d & 197.01 & $216.63(3.75)$ & $348.26(20.62)$ & $423.45(58.39)$ & 16.26 \\
\hline NPU-2e & 200.00 & $300.00(6.00)$ & $440.00(72.00)$ & - & 21.00 \\
\hline
\end{tabular}

${ }^{\mathrm{a}}$ Initial decomposition temperature by TGA measurements

${ }^{\mathrm{b}} \mathrm{Char}$ yield at $700^{\circ} \mathrm{C}$ 

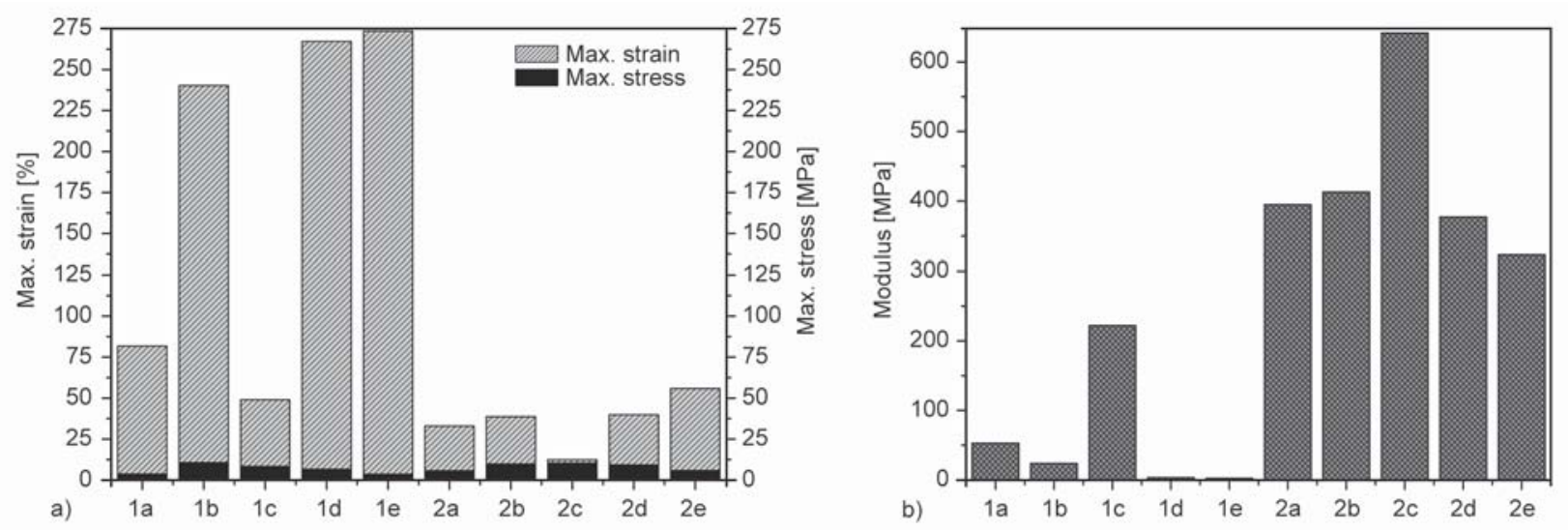

Figure 10. Mechanical properties of the samples a) Maximum stress and strain, b) Young modulus

Table 5. The mechanical properties of the polyurethane networks

\begin{tabular}{|l|c|c|c|}
\hline \multicolumn{1}{|c|}{ Sample } & $\begin{array}{c}\text { Max. stress } \\
{[\mathbf{M P a}]}\end{array}$ & $\begin{array}{c}\text { Max. strain } \\
{[\mathbf{\%}]}\end{array}$ & $\begin{array}{c}\text { Modulus } \\
{[\mathbf{M P a}]}\end{array}$ \\
\hline NPU-1a & 3.63 & 78.15 & 53.06 \\
\hline NPU-1b & 10.60 & 229.68 & 23.91 \\
\hline NPU-1c & 8.26 & 40.70 & 222.30 \\
\hline NPU-1d & 6.54 & 260.70 & 3.65 \\
\hline NPU-1e & 3.54 & 270.00 & 2.66 \\
\hline NPU-2a & 5.63 & 27.30 & 395.00 \\
\hline NPU-2b & 9.80 & 28.90 & 413.00 \\
\hline NPU-2c & 10.32 & 2.12 & 642.03 \\
\hline NPU-2d & 9.27 & 30.55 & 377.24 \\
\hline NPU-2e & 5.75 & 50.13 & 323.00 \\
\hline
\end{tabular}

networks. Also, the NPU-2 films have higher values of the stress than the corresponding NPU-1 ones. As expected, the strain varies opposite to the stress and Young's modulus since a less rigid structure can suffer a higher deformation.

\subsection{Swelling properties}

The crosslinking density was evaluated from the swelling degree values (an increase in the swelling degree shows a decrease of the crosslinking density) [17]. The measurements were done for NPU1,2-d and the data are presented in Figure 11. As can be seen NPU-1d has a higher swelling degree in all solvents compared to NPU-2d suggesting a higher crosslinking density for the latter one. These results are in agreement with $T_{\mathrm{rDA}}$ from the DSC study which is also higher for NPU-2 series related to the NPU-1 one. If the $D_{\mathrm{s}}$ values of the same film are compared, $D_{\mathrm{s}}$ of both samples increased with decreasing polarity of the solvent. The polyurethane networks obtained have a higher crosslinking density comparing with similar ones presented in literature [52].

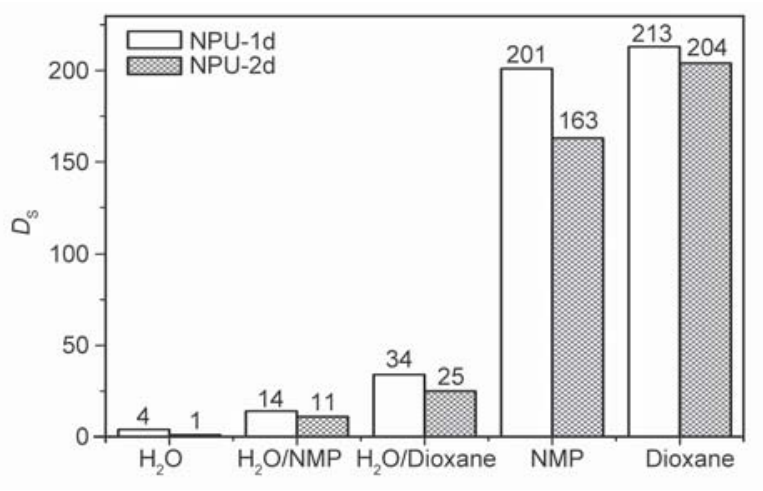

Figure 11. $D_{\mathrm{s}}$ values of NPU-1,2d in water, water/NMP $(1 / 1)$, water/dioxane (1/1), NMP and dioxane

\section{Conclusions}

New thermoreversible polyurethane networks based on $\mathrm{A}_{2} \mathrm{~B}_{3}$ monomers were successfully obtained. Their thermal, rheological and mechanical properties were studied. The crosslinking density was estimated from the degree of swelling and the NPU-2d was found to have a higher crosslinking density than NPU-1d. The thermoreversibility of the networks was observed by different methods (DSC, solution properties). By changing the trifurylic compound, the time necessary for the DA reaction to proceed decreased as proved by DSC and rheological studies. The presence of tertiary nitrogen in the structure of the crosslinked polyurethane networks influences the viscosity in the retrodienic domain of temperature probably due to the activation of free maleimide groups crosslinking. That is why in the rheological measurements the viscosity for NPU-1e increases when the one of NPU-2e reaches a plateau. Another effect of replacing the TF compound is the increase of the rDA temperature and the decrease of the initial decomposition temperature. 


\section{References}

[1] Park M-H., Jang W., Yang S-J., Shul Y., Han H.: Synthesis and characterization of new functional poly(urethane-imide) crosslinked networks. Journal of Applied Polymer Science, 100, 113-123 (2006).

https://doi.org/10.1002/app.22678

[2] Król P.: Synthesis methods, chemical structures and phase structures of linear polyurethanes. Properties and applications of linear polyurethanes in polyurethane elastomers, copolymers and ionomers. Progress in Materials Science, 52, 915-1015 (2007).

https://doi.org/10.1016/j.pmatsci.2006.11.001

[3] Majoros L. I., Dekeyser B., Haucourt N., Castelein P., Paul J., Kranenburg J. M., Rettler E., Hoogenboom R., Schubert U. S.: Preparation of polyurethane elastomers (PUEs) in a high-throughput workflow. Journal of Polymer Science Part A: Polymer Chemistry, 49, 301-313 (2011).

https://doi.org/10.1002/pola.24397

[4] Bagdi K., Molnár K., Sajó I., Pukánszky B.: Specific interactions, structure and properties in segmented polyurethane elastomers. Express Polymer Letters, 5, 417-427 (2011).

https://doi.org/10.3144/expresspolymlett.2011.41

[5] Yang Q., Ye L.: Mechanical and thermal properties of polyurethane elastomers synthesized with toluene diisocyanate trimer. Journal of Macromolecular Science Part B: Physics, 52, 138-154 (2013).

https://doi.org/10.1080/00222348.2012.695631

[6] Tan S., Abraham T., Ference D., Macosko C. W.: Rigid polyurethane foams from a soybean oil-based polyol. Polymer, 52, 2840-2846 (2011). https://doi.org/10.1016/j.polymer.2011.04.040

[7] Das S., Dave M., Wilkes G. L.: Characterization of flexible polyurethane foams based on soybean-based polyols. Journal of Applied Polymer Science, 112, 299-308 (2009).

https://doi.org/10.1002/app.29402

[8] Chiu H-T., Chang C-Y., Pan H-W., Chiang T-Y., Kuo M-T., Wang Y-H.: Characterization of polyurethane foam as heat seal coating in medical pouch packaging application. Journal of Polymer Research, 19, 9791/1-9791/12 (2012).

https://doi.org/10.1007/s10965-011-9791-3

[9] Lamba N. M. K., Woodhouse K. A., Cooper S. L.: Polyurethanes in biomedical applications. CRC Press, New York (1997).

[10] Silvestri A., Serafini P. M., Sartori S., Ferrando P., Boccafoschi F., Milione S., Conzatti L., Ciardelli G.: Polyurethane-based biomaterials for shape-adjustable cardiovascular devices. Journal of Applied Polymer Science, 122, 3661-3671 (2011).

https://doi.org/10.1002/app.34779

[11] Ignacio C., Gomes I. A. S., Oréfice R. L.: Polyurethane membranes with tunable surface properties for biomedical applications. Journal of Applied Polymer Science, 121, 3501-3508 (2011). https://doi.org/10.1002/app.34134
[12] Chattopadhyay D. K., Raju K. V. S. N.: Structural engineering of polyurethane coatings for high performance applications. Progress in Polymer Science, 32, 352-418 (2007).

https://doi.org/10.1016/j.progpolymsci.2006.05.003

[13] Tang Q., He J., Yang R., Ai Q.: Study of the synthesis and bonding properties of reactive hot-melt polyurethane adhesive. Journal of Applied Polymer Science, 128, 2152-2161 (2013).

https://doi.org/10.1002/app.38415

[14] Yang Z., Wicks D. A., Yuan J., Pu H., Liu Y.: Newly UVcurable polyurethane coatings prepared by multifunctional thiol- and ene-terminated polyurethane aqueous dispersions: Photopolymerization properties. Polymer, 51, 1572-1577 (2010). https://doi.org/10.1016/j.polymer.2010.02.003

[15] Jeong H., Zou D., Tsutsui T., Ha C-S.: Short-term degradation behaviors of light emitting diodes made of polyurethane derivative with large permanent dipoles on the side chain. Thin Solid Films, 363, 279-281 (2000).

https://doi.org/10.1016/S0040-6090(99)01009-3

[16] Behrendt G., Naber B. W.: The chemical recycling of polyurethanes (review). Journal of the University of Chemical Technology and Metallurgy, 44, 3-23 (2009).

[17] Okhay N., Mignard N., Jegat C., Taha M.: Diels-Alder thermoresponsive networks based on high maleimidefunctionalized urethane prepolymers. Designed Monomers and Polymers, 16, 475-487 (2013). https://doi.org/10.1080/15685551.2012.747166

[18] Štirn Ž., Ručigaj A., Krajnc M.: Characterization and kinetic study of Diels-Alder reaction: Detailed study on $\mathrm{N}$-phenylmaleimide and furan based benzoxazine with potential self-healing application. Express Polymer Letters, 10, 537-547 (2016).

https://doi.org/10.3144/expresspolymlett.2016.51

[19] Laita H., Boufi S., Gandini A.: The application of the Diels-Alder reaction to polymers bearing furan moieties. 1. Reactions with maleimides. European Polymer Journal, 33, 1203-1211 (1997). https://doi.org/10.1016/S0014-3057(97)00009-8

[20] Loy D. A., Wheeler D. R., McElhanon J. R., Saunders R. S.: Methods of making thermally removable polyurethanes. U.S. Patent 6403753 B1, USA (2002).

[21] Gaina V., Gaina C.: Synthesis and characterization of poly(ester-urethane-imide)s by Diels-Alder polyaddition. Polymer-Plastics Technology and Engineering, 41, 523-540 (2002). https://doi.org/10.1081/PPT-120004366

[22] Gaina C., Ursache O., Gaina V.: Re-mendable polyurethanes. Polymer-Plastics Technology and Engineering, 50, 712-718 (2011). https://doi.org/10.1080/03602559.2010.551392

[23] Ishida K., Yoshie N.: Two-way conversion between hard and soft properties of semicrystalline cross-linked polymer. Macromolecules, 41, 4753-4757 (2008). https://doi.org/10.1021/ma8008383 
[24] Ishida K., Weibel V., Yoshie N.: Substituent effect on structure and physical properties of semicrystalline Diels-Alder network polymers. Polymer, 52, 2877 2882 (2011). https://doi.org/10.1016/j.polymer.2011.04.038

[25] Oya N., Saitoh S., Furuhashi Y., Yoshie N.: Mechanical property tuning of semicrystalline network polymers by controlling rates of crystallization and crosslinking. Journal of Polymer Science Part A: Polymer Chemistry, 50, 1926-1932 (2012).

https://doi.org/10.1002/pola.25966

[26] Gaina V., Ursache O., Gaina C., Buruiana E.: Novel thermally-reversible epoxy-urethane networks. Designed Monomers and Polymers, 15, 63-73 (2012). https://doi.org/10.1163/156855511X606155

[27] Gaina C., Ursache O., Gaina V., Varganici C. D.: Thermally reversible cross-linked poly(ether-urethane)s. Express Polymer Letters, 7, 636-650 (2013). https://doi.org/10.3144/expresspolymlett.2013.60

[28] Varganici C-D., Ursache O., Gaina C., Gaina V., Simionescu B. C.: Studies on new hybrid materials prepared by both Diels-Alder and Michael addition reactions. Journal of Thermal Analysis and Calorimetry, 111, 1561-1570 (2013). https://doi.org/10.1007/s10973-012-2532-y

[29] Varganici C-D., Ursache O., Gaina C., Gaina V., Rosu D., Simionescu B. C.: Synthesis and characterization of a new thermoreversible polyurethane network. Industrial and Engineering Chemistry Research, 52, 5287 5295 (2013). https://doi.org/10.1021/ie400349b

[30] Gaina C., Gaina V., Varganici C. D.: Copoly(ester-urethane) networks containing thermoreversible bonds. Revue Roumaine de Chimie, 59, 537-544 (2014).

[31] Zhang J., Niu Y., Huang C., Xiao L., Chen Z., Yang K., Wang Y.: Self-healable and recyclable triple-shape PPDO-PTMEG co-network constructed through thermoreversible Diels-Alder reaction. Polymer Chemistry, 3, 1390-1393 (2012).

https://doi.org/10.1039/C2PY20028G

[32] Ishida K., Nishiyama Y., Michimura Y., Oya N., Yoshie N.: Hard-soft conversion in network polymers: Effect of molecular weight of crystallizable prepolymer. Macromolecules, 43, 1011-1015 (2010). https://doi.org/10.1021/ma901994v

[33] Lakatos Cs., Czifrák K., Papp R., Karger-Kocsis J., Zsuga M., Kéki S.: Segmented linear shape memory polyurethanes with thermoreversible Diels-Alder coupling: Effects of polycaprolactone molecular weight and diisocyanate type. Express Polymer Letters, 10, 324-336 (2016).

https://doi.org/10.3144/expresspolymlett.2016.30

[34] Ursache O., Găină C., Găină V., Varganici C. D.: Thermal properties of thermoresponsive networks based on polyurethanes. Revue Roumaine de Chimie, 61, 379-384 (2016).
[35] Ivanov A. A., Primel'yes E.: Polymerization of maleimides in the presence of tertiary amines. Polymer Science U.S.S.R., 26, 1453-1460 (1984) https://doi.org/10.1016/0032-3950(84)90060-1

[36] Gaina V., Gaina C., Sava M., Stoleriu A., Rusu M.: Bismaleimide resins containing urethanic moieties. Journal of Macromolecular Science Part A: Pure and Applied Chemistry, 34, 2435-2449 (1997). https://doi.org/10.1080/10601329708010058

[37] Gaina C., Ursache O., Gaina V., Varganici C. D.: Poly (urethane-benzoxazine)s. Journal of Polymer Research, 21, 586/1-586/11 (2014). https://doi.org/10.1007/s10965-014-0586-1

[38] Du P., Wu M., Liu X., Zheng Z., Wang X., Joncheray T., Zhang Y.: Diels-Alder-based crosslinked self-healing polyurethane/urea from polymeric methylene diphenyl diisocyanate. Journal of Applied Polymer Science, 131, 40234/1-40234/7 (2014).

https://doi.org/10.1002/app.40234

[39] Mallek H., Jegat C., Mignard N., Taha M., Abid M., Abid S.: One-step synthesis of PCL-urethane networks using a crosslinking/de-crosslinking agent. Journal of Macromolecular Science Part A: Pure and Applied Chemistry, 50, 728-737 (1997). https://doi.org/10.1080/10601325.2013.792218

[40] Ursache O., Gaina C., Gaina V., Tudorachi N., Bargan A., Varganici C. D., Rosu D.: Studies on Diels-Alder thermoresponsive networks based on ether-urethane bismaleimide functionalized poly(vinyl alcohol). Journal of Thermal Analysis and Calorimetry, 118, 14711481 (2014). https://doi.org/10.1007/s10973-014-4041-7

[41] Chen X., Dam M. A., Ono K., Mal A., Shen H., Nutt S. R., Sheran K., Wudl F.: A thermally re-mendable crosslinked polymeric material. Science, 295, 1698-1702 (2002).

https://doi.org/10.1126/science.1065879

[42] Matějka L.: Rheology of epoxy networks near the gel point. Polymer Bulletin, 26, 109-116 (1991). https://doi.org/10.1007/BF00299355

[43] Laza J. M., Julian C. A., Larrauri E., Rodriguez M., Leon L. M.: Thermal scanning rheometer analysis of curing kinetic of an epoxy resin: 2 . An amine as curing agent. Polymer, 40, 35-45 (1999). https://doi.org/10.1016/S0032-3861(98)00217-1

[44] Karkanas P. I., Partridge I. K.: Cure modeling and monitoring of epoxy/amine resin systems. II. Network formation and chemoviscosity modeling. Journal of Applied Polymer Science, 77, 2178-2188 (2000). https://doi.org/10.1002/10974628(20000906)77:10<2178::AID-APP11>3.0.CO;2-0

[45] De La Caba K., Guerrero P., Eceiza A., Mondragon I.: Kinetic rheological studies of two unsaturated polyester resins cured at different temperatures. European Polymer Journal, 33, 19-23 (1997). https://doi.org/10.1016/S0014-3057(96)00110-3 
[46] Nair C. P. R., Ninan K. N.: Rheological cure characterization of phosphazene-triazine polymers. Journal of Applied Polymer Science, 88, 908-914 (2003). https://doi.org/10.1002/app.11705

[47] Chiou B-S., Khan S. A.: Real-time FTIR and in situ rheological studies on the UV curing kinetics of thiol-ene polymers. Macromolecules, 30, 7322-7328 (1997). https://doi.org/10.1021/ma9708656

[48] Boey F. Y. C., Qiang W.: Determining the gel point of an epoxy-hexaanhydro-4-methylphthalic anhydride (MHHPA) system. Journal of Applied Polymer Science, 76, 1248-1256 (2000).

https://doi.org/10.1002/(SICI)10974628(20000523)76:8<1248::AID-APP5>3.0.CO;2-0

[49] Hu X., Fan J., Yue C. Y.: Rheological study of crosslinking and gelation in bismaleimide/cyanate ester interpenetrating polymer network. Journal of Applied Polymer Science, 80, 2437-2445 (2001).

https://doi.org/10.1002/app.1350
[50] Winter H. H., Chambon F.: Analysis of linear viscoelasticity of a crosslinking polymer at the gel point. Journal of Rheology, 30, 367-382 (1986).

https://doi.org/10.1122/1.549853

[51] Bose K. R., Kötteritzsch J., Garcia J. S., Hager D. M., Schubert S. U., van der Zwaag S.: A rheological and spectroscopic study on the kinetics of self-healing in a single-component Diels-Alder copolymer and its underlying chemical reaction. Journal of Applied Polymer Science Part A: Polymer Chemstry, 52, 1669-1675 (2014). https://doi.org/10.1002/pola.27164

[52] Yoshioka Y., Oikawa D., Shimasaki T., Teramoto N., Shibata M.: Gelation behavior and thermal and mechanical properties of polymer network formed by the Diels-Alder reaction of furan- and maleimide-terminated four-arm star-shaped ethylene glycol oligomers. Colloid and Polymer Science, 293, 1059-1071 (2015). https://doi.org/10.1007/s00396-014-3492-5 